This is the peer reviewed version of the following article: Journal of Food Science Volume73,

Issue7 (2008) Pages C526-C532, which has been published in final form at https://doi.org/10.1111/

j.1750-3841.2008.00893.x. This article may be used for non-commercial purposes in accordance with

Wiley Terms and Conditions for Self-Archiving.

\title{
Characterization of Asparagus Lignin by HPLC
}

Jaramillo-Carmona S, Fuentes-Alventosa JM, Rodríguez-Gutiérrez G, Guillén-Bejarano

R, Fernández-Bolaños J, Jiménez-Araujo A, Rodríguez-Arcos R.

Instituto de la Grasa (CSIC), Food Biotechnology Department, Avenida Padre García

Tejero 4, 41012 Sevilla, Spain

Corresponding author:

Dra. Rocío Rodríguez-Arcos

Instituto de la Grasa (CSIC), Food Biotechnology Department. Avenida Padre

García Tejero 4, 41012 Sevilla, Spain

Phone (+34) 954692516

Fax (+34) 954691262

rrodri@,cica.es

Running head : Asparagus lignin ...

Journal section : Food Chemistry 


\section{Abstract}

Lignin is the cell wall component most frequently associated with hardening. Its

3 characterisation and quantification is very important to understand the biochemical

4 modifications related to the changes in texture of vegetables such as asparagus

5 (Asparagus officinalis), in which this organoleptic attribute is a very important quality

6 factor. In this study, asparagus lignin from the basal sections of fresh and stored spears

7 was analysed by using both methods, the traditional (Klason lignin) and the recently

8 developed derivatization followed by reductive cleavage (DFRC) method. The latter is a

9 simple and reproducible technique for lignin characterization based on a degradation

10 procedure that produces analysable monomers and dimers by cleaving $\alpha$ - and $\beta$-aryl

11 ethers in lignins. The primary monomers derived from DFRC degradation of lignins are

12 essentially p-coumaryl peracetate, coniferyl peracetate and sinapyl peracetate.

13 In order to evaluate the efficiency of the DFRC method, our investigations have

14 been carried on distinct sample types, including wood (data not shown), straw, and

15 asparagus samples. The results have confirmed that lignin composition is affected by

16 plant nature. It has been found that whereas wood samples mostly contain coniferyl units,

17 plant foods such as straw and asparagus contain both coniferyl and guaiacyl units.

19 Key words: lignin composition, asparagus toughening, DFRC method, HPLC, Klason 20 lignin

INTRODUCTION

The chemical basis of hardening is related with modifications of the cell wall

24 composition and has traditionally been associated with lignification (Salunkhe and Desai 
25 1984; Smith and Stanley 1987; Everson and others 1992). The presence of lignin is

26 confined to vascular plants, where it is mainly deposited in cell walls of tissues involved

27 in mechanical support or in water conduction such as xylem, sclerenchyma, phloem fibers

28 and periderm. The effect of lignin on cell wall properties is thought to be mediated by the

29 hydrophobicity of lignin and its incrustation and attachment to structural polysaccharides

30 and proteins (Grabber and others 1996). Lignin is derived from the dehydrogenative

31 polymerization of three different hydroxy-cinnamyl alcohols (or monolignols): $p$ -

32 coumaryl alcohol, coniferyl alcohol and sinapyl alcohol. They give rise to the p-

33 hydroxyphenyl $(\mathrm{H})$, guaiacyl $(\mathrm{G})$ and syringyl (S) units of the lignin polymer,

34 respectively. The monolignols are C6-C3 phenylpropanoids and differ from each other

35 only by their degree of methoxylation. In lignin, the C6-C3 units are interconnected by

36 several types of ether and carbon-carbon linkages, but their relative number is not clearly

37 established because different analytical methods give distinct results. Only a fraction of

38 the lignin polymer is solubilized by most of the chemical degradation methods and

39 isolation of parts of lignin always causes chemical changes in the structure (Monties

40 1998). An artificial lignin polymer, called dehydrogenation polymer (DHP) can be

41 formed by dehydropolymerization of the lignin precursors, and it has been used to

42 investigate in vitro lignin biosynthesis and structure (Freudenberg and Neish 1968).

43 However, those synthetic lignins generated by oxidative polymerisation of $\mathrm{p}-$

44 hydroxycinnamyl alcohols differ structurally from natural lignins and they do not

45 adequately model the three dimensional structure of lignified walls. The difficulty in

46 obtaining knowledge about lignin structures in vivo is accompanied by the fact that lignin

47 content and composition vary among plants. In general, the lignin of dicotyledonous

48 gymnosperms results from the polymerization of coniferyl alcohol, whereas angiosperm 
49 lignin is composed of both coniferyl and sinapyl alcohol. Monocotyledonous plants

50 usually contain the three types of monomers (Baucher and others 1998). Different

51 compositions can also be found within the same plant, among cell types of a single tissue.

52 In asparagus, the lignin content is approximately threefold higher at the bottom of the

53 spear than that at the top (Hennion and others 1992).

54 In this work, lignin was quantified from the residue left after saponification of cell

55 wall material. The recently developed derivatization followed by reductive cleavage

56 (DFRC) method was used for lignin analysis. This procedure has been optimised for the

57 characterisation of the degradation products from both wood and grass cell walls. The

58 DFRC method is a degradation procedure that produces analysable monomers and dimers

59 by cleaving $\alpha$ - and $\beta$-aryl ethers in lignins (Ralph and Lu 1998). Lignin components were

60 identified by HPLC, after being released from asparagus tissues. As it has previously

61 been reported, it is difficult to achieve the measurement of lignin in herbaceous plants,

62 including asparagus. Interferences of other cell wall components such as proteins and

63 simple phenolics can overestimate the quantity of lignin; and on the other hand,

64 incomplete hydrolysis of lignin may give erroneous lower values. This seemed to be the

65 situation when asparagus lignin contents were analysed by using the DFRC method. In

66 order to improve those results different factors have been investigated: derivatization

67 temperature, lengthening $\mathrm{AcBr}$ treatment, particle size, reagents volume, and nature of

68 sample. The objectives of the present work are to improve measurement of lignin by

69 optimizing the DFRC method and to determine changes in lignin components after

70 asparagus storage.

72 MATERIALS AND METHODS 


\section{Plant Material}

Asparagus officinalis, var. Franklin, was obtained from a local commercial asparagus producer. Spears were cut to a distance of $18 \mathrm{~cm}$ from the tip, and then stored for 16 days at $4^{\circ} \mathrm{C}$ in airtight containers with an air current of saturated humidity. Fresh and stored samples were divided in three cylindrical portions of $5 \mathrm{~cm}$ length (apical, middle and basal) and lignin was determined in the cell wall material prepared from each of the three sections.

Straw samples from wheat (Straw-W) and barley (Straw-B) were extracted for alcohol insoluble residue (AIR) as described by Martín-Cabrejas and others (1994).

\section{Lignin quantification by the Derivatization Followed by Reductive Cleavage method} Preparation of Cell Wall Material Fresh and stored green asparagus $(100 \mathrm{~g})$ was blended in $15 \mathrm{~g} \mathrm{~L}^{-1}$ aqueous lauryl sulphate (SDS) containing $5 \mathrm{mM} \mathrm{Na}_{2} \mathrm{~S}_{2} \mathrm{O}_{5}$ with an Omni-mixer homogeniser for $5 \mathrm{~min}$. A few drops of octanol were added to reduce foaming. The homogenate was filtered through a $100 \mu \mathrm{m}$ nylon mesh and the residue was ball-milled (Pascall, $0.5-\mathrm{L}$ pot) at $1^{0} \mathrm{C}$ in $5 \mathrm{~g} \mathrm{~L}{ }^{-1}$ SDS containing $3 \mathrm{mM} \mathrm{Na}_{2} \mathrm{~S}_{2} \mathrm{O}_{5}$ for $12 \mathrm{~h}$ at $60 \mathrm{rpm}$. After filtering the homogenate through a $75-\mu \mathrm{m}$ nylon mesh, the residue was suspended in cold water containing $3 \mathrm{mM}$ $\mathrm{Na}_{2} \mathrm{~S}_{2} \mathrm{O}_{5}$, homogenized for $5 \mathrm{~min}$ and re-filtered. The latter procedure was repeated two times. Finally, the cell wall material (CWM) was further extracted with hot ethanol, for $10 \mathrm{~min}$, to remove any alcohol soluble phenolics, washed with acetone and then air dried (Martín-Cabrejas and others 1994).

DFRC Lignin Quantification and Characterisation by the derivatisation followed by reductive cleavage 
Wall-bound phenolics were released by sequential alkaline hydrolysis of isolated

98 CWM as described by Hartley and Morrison (1991). The residue remaining after

99 saponification of cell wall material was used for lignin analysis. Lignin composition was

100 determined by modifying the derivatization followed by reductive cleavage (DFRC)

101 procedure (Lu and Ralph 1997). To a round bottom flask containing lignin sample (the

102 residue remaining after saponification of cell wall material), acetyl bromide (AcBr) stock

103 solution (AcBr:acetic acid $20: 80$ by volume) was added. The mixture was heated at $50^{\circ} \mathrm{C}$,

104 for $3 \mathrm{~h}$, and then the solvent was removed by rotary evaporation at $40^{\circ} \mathrm{C}$. Prior to the

105 establishment of these conditions, different variables have been investigated for

106 optimisation: derivatization temperature $\left(30-60^{\circ} \mathrm{C}\right)$, lengthening $\mathrm{AcBr}$ treatment $(1-5 \mathrm{~h})$,

107 particle size (normally ground and freezer-milled samples), reagents volume (6-96 mL)

108 and nature of sample (asparagus, wood and straw).

109 The residue was dissolved in the acidic reduction solvent (dioxane:acetic

110 acid:water 5:4:1). Zinc powder (100 mg) was added to the well-stirred solution. Stirring

111 was continued for $30 \mathrm{~min}$. The mixture was filtered through glass fibre paper (GF-A

112 Whatman, Maidstone, U.K.) and the filtrate was evaporated under vaccum, at $40^{\circ} \mathrm{C}$, to

113 dryness. The residue was used for HPLC quantification. The degraded products were

114 dissolved in $1 \mathrm{ml}$ of methanol and trans-cinnamic acid $(16 \mu \mathrm{g})$ was added as internal

115 standard. $100 \mathrm{ul}$ of this solution was used for HPLC analysis.

116 Monoacetylated and diacetylated monolignols released from asparagus lignin

117 were identified by HPLC and their retention times and spectrums were compared with

118 those of authentic compounds. Monolignols were separated by using a SPHERISORB "S

119 Chiral” column (25 cm x $4.6 \mathrm{~mm}$ i.d., $5 \mathrm{~mm}$, Capital HPLC Ltd., Broxburn, West

120 Lothian, U.K.). The elution was performed with progressive increasing acetonitrile levels 
121 in $1 \mathrm{mM}$ trifluoracetic acid (TFA). The most suitable gradient profile for separation of

122 coniferyl and sinapyl acetates was: using solvent A (water plus TFA to $1 \mathrm{mM}$ ) and

123 solvent B (acetonitrile neutral plus TFA to $1 \mathrm{mM}$ ) in the following programme: initially A

$124100 \%$, linear gradient over $50 \mathrm{~min}$ to A $65 \%$, B 35\%, exponential gradient over 15 min to

125 B $100 \%$, held isocratically at B $100 \%$ for $10 \mathrm{~min}$, exponential gradient over 10 min to A

$126100 \%$, held isocratically to A $100 \%$ for $5 \mathrm{~min}$. The flow rate was maintained at $1 \mathrm{ml} / \mathrm{min}$

127 and the solvents were sparged with helium prior to use. Detection was with a Perkin

128 Elmer Model 235C DAD. Quantitation was by integration of peak-areas at $265 \mathrm{~nm}$, with

129 reference to calibration s made using known amounts of pure compounds.

130 Trans-hydroxycinnamyl acetates $\mathbf{H}_{\mathrm{t}}, \mathbf{G}_{\mathrm{t}}$ and $\mathbf{S}_{\mathrm{t}}$ were prepared from parent

131 hydroxycinnamyl alcohols by acetylation, and these compounds were used as standards to

132 calculate lignin composition of plant cell walls.

\section{Klason Lignin Quantification}

134 Klason lignin was calculated as described by Theander and Westerlund (1986)

135 with some modification. Both asparagus CWM and straw AIR, prepared as explained

136 above, were analysed. A ground sample (150-250 mg) was weighed into a glass tube (100

$137 \mathrm{ml}$ ), and $3 \mathrm{ml}$ of $72 \% \mathrm{H}_{2} \mathrm{SO}_{4}$ was added. The mixture was incubated at room temperature

138 for 3 hours, shaking frequently. After adding $36 \mathrm{ml}$ distilled water, the suspension was

139 mixed and incubated at $100^{\circ} \mathrm{C}$, for $2 \frac{1}{2}$ hours. The hydrolysis mixture was filtered

140 through a Pyrex No. 2 glass filter, and the residue was washed with hot water, until free

141 of acid. The glass filter, containing the filtered material, was dried, until constant weight,

142 and Klason lignin was determined gravimetrically.

143

144 Statistical Analysis 
146 multivariate analysis of variance (ANOVA) followed by Fisher-LSD multicomparison

147 test. The level of significance was $P<0.05$.

149 RESULTS

150 Analysis of Plant Lignins by using a modified DFRC method

151 Lignin was characterized after degradation to analyzable monomers from native

152 lignin. The primary monomers derived from DFRC degradation of lignin samples are

153 essentially $p$-coumaryl peracetate, coniferyl peracetate and sinapyl peracetate (Fig 1).

154 HPLC chromatograms showed that major peaks arise from guaiacyl and syringyl units

155 involved in ether linkages. These units can be found as alcohol, monoacetylated

156 monolignol or diacetylated monolignol. Coniferyl, sinapyl alcohol (commercially

157 available), and p-coumaryl alcohol (provided by John Ralph) were acetylated, applied to

158 the HPLC column and eluted with an acetonitrile gradient which enabled separation of

159 alcohol, monoacetylated monolignols (A and B) and diacetylated monolignols (Fig. 2).

160 Typical retention times and response factors of these compounds are shown in Table 1.

161 The presence of these compounds can be assessed through analysis of the spectral

162 properties. The individual absorption spectrum of each compound was recorded, and the

163 spectrums from $p$-coumaryl, coniferyl and sinapyl derivatives shown to be significantly

164 different. In the spectra of $p$-coumaryl acetate, two peaks of absorbance maximum $\left(\lambda_{\max }\right)$

165 were found, at $201 \mathrm{~nm}$ and $254 \mathrm{~nm}$, and the absorbance minimum was at $225 \mathrm{~nm}$. All

166 coniferyl derivatives exhibited similar profiles: two absorbance maxima, at $214 \mathrm{~nm}$ and

$167260 \mathrm{~nm}$, and a small shoulder at $300 \mathrm{~nm}$. The absorbance minimum was at $240 \mathrm{~nm}$ (Fig. 1

168 and Table 1). 
170 to coniferyl compounds. Although also two absorbance maxima are present, they elute

171 slightly later, at 220 and $265 \mathrm{~nm}$, and there is no shoulder (Fig. 1).

172 The response factors (RF) have been based on gravimetric quantitation of small

173 quantities of pure standards. The RF values, relative to the internal standard (trans-

174 cinnamic acid) range from 0.1-0.4, reflecting the different absorption maxima of the $p$ -

175 coumaryl, coniferyl and sinapyl alcohol and acetates (Table 1).

176

\section{Quantification and Characterization of Asparagus Lignin}

178 As it has been reported previously (Rodríguez and others 1999, Rodríguez-Arcos

179 and others 2002), the deposition of lignin that occurs during asparagus post-harvest

180 storage is located in the middle and basal sections of the spear. In the present work, the

181 values of lignin content for the middle and basal sections were not significantly different

$182(P<0.05)$, using either the Klason or the DFRC method (Table 2). Klason lignin values

183 from the middle and basal section of fresh asparagus were 87.3 and $89.6 \mathrm{mg} / \mathrm{g}$ cell wall.

184 After storage, those values increased to 110.6 and $107.0 \mathrm{mg} / \mathrm{g}$ cell wall. The values

185 obtained by using the DFRC method were 2.73 and $3.06 \mathrm{mg} / \mathrm{g}$ cell wall for the middle

186 and basal sections from fresh asparagus, and 4.13 and $4.21 \mathrm{mg} / \mathrm{g}$ cell wall for the

187 respective stored samples. So, for investigating asparagus lignin composition, the cell

188 wall material isolated from the basal section was used. In addition to asparagus, two

189 different straw samples from wheat and barley have been investigated, in order to prove

190 the efficiency of the DFRC method on both herbaceous and woody (straw) samples.

191 Preliminary assays to compare different methods that have traditionally been used

192 for lignin analysis were performed (results not shown). Based on the results of these 
193 assays, in this study, acetyl bromide (AcBr) was used for hydrolysis of the cell wall

194 material. Not only the content (Table 2) but also the composition of lignin within

195 asparagus cell walls was determined. Typical composition of lignins from asparagus and

196 straw samples are shown in table 3. Lignin was quantified as the sum of the different

197 monolignols detected by HPLC analysis.

198 It was found that asparagus lignin consisted mainly of coniferyl (60\%) and sinapyl

$199(40 \%)$ units, and the majority of these were present as monoacetylated and diacetylated

200 monolignols. The monoacetylated compounds comprised $67 \%$ of the total coniferyl and

$20177 \%$ of the total sinapyl complement.

202 As it can be observed in Table 3, the use of the DFRC method for the

203 quantification of lignin, provides additional information about its composition.

205 Optimization and Evaluation of the DFRC Method

206 As it has previously been reported, it is difficult to reliably quantify lignin in

207 herbaceous plants, including asparagus (Rodríguez and others 1999). Interferences by

208 other cell wall components such as proteins and simple phenolics can result in

209 overestimation of the quantity of lignin, and on the other hand, incomplete hydrolysis of

210 lignin may result in underestimation (Südekum and others 1997). The second seems to be

211 the situation when asparagus lignin contents were analysed by using the DFRC method.

212 In order to improve the quantification method different factors were investigated:

213 derivatization temperature, length of $\mathrm{AcBr}$ treatment, particle size, reagents volume, and

214 nature of plant material. In relation to temperature and length of the treatment (Table 4),

215 our results are consistent to those reported by Hatfield and others (1999). They suggested

216 that treatment of samples at $50^{\circ} \mathrm{C}$, during $3 \mathrm{~h}$ are the optimal conditions to derivatize 
217 lignins from wood samples. Also, reducing the particle size and increasing the reagents

218 volume results in some improvements (Table 4). Straw-wheat samples that had shown to

219 be highly lignified (15\% Klason lignin) have been used to test the influence of those two

220 parameters in the recovery of lignin components: Scaling up the volume of reagents by a

221 factor of two meant an important increase of monomer yields. Successive increases of

222 solvents volume were also tested, but no improvements were observed (Table 4).

223 Grinding of the samples in a freezer-mill for $10 \mathrm{~min}$ resulted in significant increases

$224(P<0.05)$ in the yields of lignin monomers. Nevertheless, this factor did not appear as to

225 be as important as the volume of reagents (Table 4).

226 It was observed that some residue remained after $\mathrm{AcBr}$ treatment of both

227 normally-ground and freezer-milled samples. Scaling up the amount of solvents by a

228 factor of 2 resulted in a complete solubilization of the samples, forming a clear solution.

229 It has been suggested that there is considerable heterogeneity in the amount and

230 nature of the lignin deposited in walls of different cell types and in different parts of

231 individual cell walls (Chesson and others 1997). This study has confirmed that not only

232 the total content of lignin, but also its composition and structure can differ among

233 different plant materials and tissue types.

234 Among the different factors that influence lignin monomers yields, our

235 investigations revealed that particle size and reagents volume were the most determinant.

236 The results from the comparative analysis of different plant samples (straw-wheat, straw-

237 barley, fresh asparagus and stored asparagus) that were extracted with 6 and $12 \mathrm{~mL}$ of

238 reagents, and using two different milling treatments are shown in Table 5. It can be

239 concluded that the best conditions for characterizing plant lignins consisting on grinding 
240 the samples (50 mg cell wall material) in a freezer-milling, for $10 \mathrm{~min}$, and then

241 extracting them with $12 \mathrm{~mL}$ of DFRC reagents.

242 As explained above, in asparagus, the lignin content increased from the top to the

243 bottom of the spear. Besides, significant differences $(P<0.05)$ were found in relation to

244 both lignin content and composition by comparison of the middle and bottom sections

245 from fresh and stored asparagus (Tables 2 and 5). It can be assumed that differences in

246 cell wall lignin composition will affect the mechanical properties of asparagus tissues.

247 Our results are consistent with those reported by Terashima and Fukushima

248 (1989), who suggested a mechanism that regulates the deposition of syringyl and guaicyl

249 units in lignin. The compositional changes on lignin constituents may affect the

250 extractability of the different lignins. Bernard-Vailhé and others (1998) found that in

251 transgenic tobacco plants with reduced cinnamyl alcohol dehydrogenase (CAD) activity,

252 which was supposed to decrease the formation of hydroxy-cinnamyl alcohols and,

253 therefore, reduce the lignin content, the lignin contents did not change. However, there

254 was an important reduction in the syringyl/guaicyl molar ratio, suggesting modifications

255 in lignin composition and structure. For similar lignin content, the decrease in the

256 proportion of syringyl units meant an increase in the accessibility of hydrolytic enzymes,

257 such as glycanases, to the substrate and therefore an improvement of the lignin

258 digestibility (Reeves 1987; Jung and Deetz 1993).

259 This study on wood, straw and asparagus has confirmed the correlation between

260 syringyl units and degradability. The application of the DFRC method, which is a simple

261 and reproducible technique for lignin characterization, on woody (straw) lignins meant a

262 complete solubilization of the samples, whereas an insoluble residue was left for

263 asparagus samples, even when the samples were extracted with higher amounts of 
264 solvent. Further characterization of lignin composition revealed that no syringyl units

265 were present in wood samples and that the percent of syringyl units was lower in lignins

266 from straw (32\%), than in asparagus lignins (40\%). These results strongly suggest that

267 lignin structure is important for the extent, and possibly, the rate of cell wall

268 degradability.

269 Regarding lignin quantification, the values of lignin calculated as recovery of its

270 constituent monomers were much lower than the results obtained from the traditional

271 methods such as Klason lignin. These discrepancies were found for both woody and

272 asparagus samples, but were larger in the latter, in which the content of DFRC lignin was

273 less than $10 \%$ of Klason lignin.

274 The hard fact remains that the measurement of lignins in plant material is difficult

275 to achieve and there is no general method to quantify this complex cell wall polymer.

276 However, the application of the DFRC modified procedure provides interesting

277 information about structural characteristics of lignins isolated from both wood and

278 herbaceous plants.

279 Covalent intermolecular bonds may also be implied in the different solubility of

280 plant lignins, particularly those between lignin and carbohydrate. Further studies are

281 needed to understand which structures in addition to syringyl units have an effect on cell

282 wall degradability. Piquemal and others (1998) reported that the increase in the syringyl

283 over guaiacyl $(\mathrm{S} / \mathrm{G})$ ratio was accompanied by increases of cell wall-bound phenolics,

284 mostly ferulic acid, in stems of tobacco plants. The occurrence of cell wall-linked ferulic

285 acid in substantial amounts is a specific feature of grasses, whereas it is usually detected

286 as a minor or trace cell wall component in the xylem of dicotyledons. Recent

287 investigations have demonstrated that cell walls of asparagus spears contain significant 
288 quantities of phenolic esters, particularly FA and its dehydrodimers, which increase

289 considerably during post-harvest storage. These findings are consistent with a role of

290 phenolic esters in the maturation and storage-related toughening of asparagus (Rodríguez-

291 Arcos and others 2002, 2004).

292 The attachment mode of ferulic acid to the cell wall is through ester bonds,

293 cleaved by mild alkaline hydrolysis (Jacquet and others 1995; Ralph and others 1994).

294 Nevertheless there may be other modes of incorporation of these acids, based on their

295 enzymatic dehydrogenation to phenoxy radicals. These radicals are actually prone to

296 participating in a variety of ether and carbon-carbon interunit linkages, resulting in the

297 cross-linking of distinct cell wall polymers and thus in the strengthening of the

298 lignocellulosic material. Further investigations are currently being developed in order to

299 isolate and characterize the phenolic ethers that can participate in the formation of cross-

300 links between polysaccharides and lignin within cell walls, which we have recently

301 detected in asparagus tissues.

\section{CONCLUSION}

304 Our most recent investigations on asparagus toughening (Rodríguez-Arcos and

305 others 2002, 2004) provide evidence that the deposition of lignin during asparagus

306 storage is not the key point in the process of toughening that this vegetable suffers. So,

307 gravimetric determinations of lignin by using the Klason method are not the most suitable

308 system since there are many other components (polysaccharides, proteins, other

309 phenolics) that can interfere with those measurements in asparagus tissues. Modifications

310 in cell wall structure, mainly formation of ferulic cross-links between different polymers,

311 seem to be much more significant than the increase of lignin in asparagus toughening. So, 
312 future research on this subject should be focused in gaining further knowledge about the

313 participation of lignin constituents in the formation of those cross-links, and for this

314 purpose the structural information that the DFRC provides is of great interest.

315

\section{REFERENCES}

317 Baucher M, Monties B, Van Montagu M, Boerjan W. 1998. Biosynthesis and genetic

318 engineering of lignin. Critical Rev Plant Sci 17:125-97.

319 Bernard-Vailhé MA, Besle JM, Maillot MP, Cornu A, Halpin C, Knight M. 1998. Effect

320 of down-regulation of cinnamyl alcohol dehydrogenase on cell wall composition and on

321 degradability of tobacco stems. J Sci Food Agric 76:505-14.

322 Chesson A, Provan GJ, Russell W, Scobbie L. 1997. Characterisation of lignin from

323 parenchyma and sclerenchyma cell walls of the maize internode. J Sci Food Agric 73:10-

3246.

325 Everson HP, Waldron KW, Geeson JD, Browne KM. 1992. Effects of modified

326 atmospheres on textural and cell wall changes of asparagus during shelf-life. Intl J Food

327 Sci Technol 27:187-99.

328 Freudenberg K, Neish AC. 1968. Constitution and Biosynthesis of Lignin. Berlin:

329 Springer-Verlag. 122 p.

330 Grabber JH, Ralph J, Hatfield RD, Quideau S, Kuster T, Pell AN. 1996. Dehydrogenation

331 polymer-cell wall complexes as a model for lignified grass walls. J Agric Food Chem

$332 \quad 44: 1453-9$.

333 Hartley RD, Morrison WH. 1991. Monomeric and dimeric phenolic acids released from

334 cell walls of grasses by sequential treatment with sodium hydroxide. J Sci Food Agric $335 \quad 55: 365-75$. 
336 Hatfield RD, Grabber J, Ralph J, Brei K. 1999. Using the acetyl bromide assay to

337 determine lignin concentrations in herbaceous plants: some cautionary notes. J Agric

338 Food Chem 47:628-32.

339 Hennion S, Little CHA, Hartmann C. 1992. Activities of enzymes involved in

340 lignification during the postharvest storage of etiolated asparagus spears. Physiol Plant

$341 \quad 86: 474-8$.

342 Jacquet G, Pollet B, Lapierre C, Mhamdi F, Rolando C. 1995. New ether-linked ferulic

343 acid-coniferyl alcohol dimers identified in grass straws. J Agric Food Chem 43:2746-51.

344 Jung HJG, Deetz DA. 1993. Cell wall lignification and degradability. In: Jung HG,

345 Buxton DR, Hatfield RD, Ralph J, editors. Forage cell wall structure and digestibility.

346 Am Soc Agron. p 315-46.

347 Lu F, Ralph J. 1997. Derivatization followed by reductive cleavage (DFRC method), a

348 new method for lignin analysis: protocol for analysis of DFRC monomers. J Agric Food

349 Chem 45:2590-2.

350 Martin-Cabrejas MA, Waldron KW, Selvendran RR. 1994. Cell wall changes in Spanish

351 pear during ripening. J Plant Physiol 144:541-8.

352 Monties B. 1988. Preparation of dioxane lignin fractions by acidolysis. Meth Enzymol

353 161:31-5.

354 Piquemal J, Lapierre C, Myton K, O'Conell A, Schuch W, Grima-Pettenati J, Boudet

355 AM. 1998. Down-regulation of cinnamoyl-CoA reductase induces significant changes of

356 lignin profiles in transgenic tobacco plants. Plant J 13:71-83.

357 Ralph J, Lu F. 1998. The DFRC method for lignin analysis. 6. A simple modification for 358 identifying natural acetates on lignins. J Agric Food Chem 46:4616-9. 
359 Ralph J, Quideau S, Grabber JH, Hatfield RD. 1994. Identification and synthesis of new

360 ferulic acid dehydrodimers present in grass cell walls. J Chem Soc (Perkin trans) 1:3485-

36198.

362 Reeves JB. 1987. Lignin and fiber compositional changes in forages over a growing

363 season and their effects on in vitro digestibility. J Dairy Sci 70:1583-94.

364 Rodríguez R, Jiménez A, Guillén R, Heredia A, Fernández-Bolaños J. 1999. Postharvest

365 changes in white asparagus cell wall during refrigerated storage. J Agric Food Chem

$366 \quad 47: 3551-7$.

367 Rodríguez-Arcos R, Smith AC, Waldron KW. 2002. Effect of storage on wall-bound

368 phenolics in green asparagus. J Agric Food Chem 50:3197-203.

369 Rodríguez-Arcos R, Smith AC, Waldron KW. 2004. Ferulic acid cross-links in asparagus

370 cell walls in relation to texture. J Agric Food Chem 52:4740-50.

371 Salunkhe DK, Desai BB. 1984. Asparagus and artichoke. In: Postharvest biotechnology

372 of vegetables. Florida: CRC Press. p 117-127.

373 Smith JL, Stanley DW. 1987. Nonenzymatic lignification of asparagus? J Texture

374 Studies 18:339-58.

375 Südekum K-H, Voigt K, Monties B, Stangassinger M. 1997. Spectrophotometric

376 investigations on lignin in wheat (Triticum aestivum L.): influence of cell wall

377 preparation, solvent and standard. J Agric Food Chem 45:1220-8.

378 Terashima N, Fukushima K. 1989. Biogenesis and structure of macromolecular lignin in

379 the cell wall of tree xylem as studied in microautoradiography. In: Lewis NG \& Paice

380 MG, editors. Plant cell wall polymers, biogenesis and biodegradation. Washington:

381 American Chemical Society. p160-8. 
382 Theander O, Westerlund EA. 1986. Studies on dietary fiber. 3. Improved procedures for 383 analysis of dietary fiber. J Agric Food Chem 34:330-6.

384

385 Acknowledgements

386 This work was supported by the Spanish CICYT (Comisión interministerial de Ciencia y

387 Tecnología), Project AGL2007-63703/ALI; and MMA (Ministerio de Medio Ambiente),

388 Project B008/2007/1-02.5. J.M.F-A. is the holder of a grant FPI from IFAPA (Instituto de

389 Investigación y Formación Agraria y Pesquera), Junta de Andalucía (Spain) 
Table 1. Diagnostic absorption wavelengths of peaks $\left(\lambda_{\max }\right)$ and of troughs $\left(\lambda_{\min }\right)$, response factors $(\mathrm{RF})$ in relation to trans-cinnamic acid and retention times $\left(\mathrm{R}_{\mathrm{t}}\right)$ of coniferyl and sinapyl derivatives that constitutes plant lignins, analysed by HPLC.

\begin{tabular}{llccc}
\hline Compound & \multicolumn{1}{c}{$\lambda_{\max }(\mathrm{nm})$} & $\lambda_{\min }(\mathrm{nm})$ & $\mathrm{RF}$ & $\mathrm{R}_{\mathrm{t}}(\min )$ \\
\hline Coniferyl alcohol & $213.9,265.2,298.3$ & 240.9 & 0.45 & 11.6 \\
Sinapyl alcohol & $222.0,274.0$ & 245.7 & 0.20 & 15.0 \\
trans-Cinnamic acid & 276.5 & 232.0 & 1.00 & 18.4 \\
Conifeyl monoacetylated A & $212.6,253.8,294.9$ & 236.2 & 0.11 & 19.9 \\
Sinapyl monoacetylated A & $219.3,263.2$ & 239.6 & 0.19 & 23.8 \\
Coniferylmonoacetylated B & $214.6,267.3,301.7$ & 243.0 & 0.11 & 30.0 \\
Sinapyl monoacetylated B & $219.3,263.2$ & 239.0 & 0.20 & 32.7 \\
p-Coumaryl diacetylated & $201.0,254.0$ & 225.0 & 0.05 & 38.6 \\
Coniferyl diacetylated & $214.6,256.8,297.0$ & 237.6 & 0.11 & 41.7 \\
Sinapyl diacetylated & $219.3,265.2$ & 239.0 & 0.19 & 44.3 \\
\hline
\end{tabular}

Table 2. Lignin content from different plant materials (\%cell wall)

\begin{tabular}{lccccc}
\hline & \multicolumn{2}{c}{ Fresh asparagus } & & \multicolumn{2}{c}{ Stored asparagus } \\
& Klason & DFRC & & Klason & DFRC \\
\cline { 2 - 3 } \cline { 5 - 6 } TOP & $6.59 \pm 0.29$ & $0.18 \pm 0.02$ & & $6.51 \pm 0.21$ & $0.26 \pm 0.04$ \\
MIDDLE & $8.73 \pm 0.40$ & $0.27 \pm 0.04$ & & $11.06 \pm 0.46$ & $0.41 \pm 0.05$ \\
BASAL & $8.96 \pm 0.24$ & $0.31 \pm 0.03$ & & $10.70 \pm 0.27$ & $0.42 \pm 0.06$ \\
Straw-W & $15.51 \pm 0.99$ & $2.36 \pm 0.22$ & & & \\
Straw-B & $13.98 \pm 0.69$ & $1.76 \pm 0.19$ & & & \\
\hline W: & & & & &
\end{tabular}

W: wheat, B: barley

Data are the mean of three replicates 
Table 3. Proportions of lignin degradation products from several plant materials

\begin{tabular}{lcccc}
\hline & & \multicolumn{2}{c}{ Lignin composition (\%Relative) } & \\
& Straw-W & Straw-B & Fresh asparagus & Stored asparagus \\
\cline { 2 - 5 } Coniferyl alcohol & n.d & n.d. & n.d. & n.d. \\
Conifeyl monoacetylated & 35 & 33 & 41 & 40 \\
Coniferyl diacetylated & 31 & 30 & 20 & 19 \\
Sinapyl alcohol & 14 & 13 & n.d. & n.d. \\
Sinapyl monoacetylated & 7 & 7 & 30 & 33 \\
Sinapyl diacetylated & 10 & 8 & 9 & 8 \\
p-Coumaryl diacetylated & 3 & 9 & n.d. & n.d. \\
\hline
\end{tabular}

$\mathrm{W}$ : wheat, B: barley

n.d.: no detected

Data are the mean of three replicates 
Table 4. Effects of temperature, time, volume of acetyl bromide reagents and particle size on lignin analysis by the DFRC method on straw-wheat sample

\begin{tabular}{|c|c|c|c|c|c|c|c|}
\hline Temperature & Lignin $\%$ & Time (h) & Lignin\% & volume (ml) & Lignin $\%$ & Particle size & Lignin $\%$ \\
\hline $40^{\circ} \mathrm{C}$ & $1.42 \pm 0.13^{\mathrm{a}}$ & 1 & $1.86 \pm 0.16^{\mathrm{a}}$ & 6 & $0.54 \pm 0.04^{\mathrm{a}}$ & N.G., 5 min & $1.62 \pm 0.10^{\mathrm{a}}$ \\
\hline $50^{\circ} \mathrm{C}$ & $2.36 \pm 0.17^{b}$ & 2 & $1.96 \pm 0.13^{\mathrm{a}}$ & 12 & $2.36 \pm 0.17^{\mathrm{b}}$ & F.M., 5 min & $2.28 \pm 0.14^{b}$ \\
\hline $60^{\circ} \mathrm{C}$ & $2.38 \pm 0.08^{b}$ & 3 & $2.36 \pm 0.17^{b}$ & 24 & $2.32 \pm 0.21^{\mathrm{b}}$ & N.G., $10 \mathrm{~min}$ & $1.93 \pm 0.05^{\mathrm{c}}$ \\
\hline $70^{\circ} \mathrm{C}$ & $2.35 \pm 0.11^{\mathrm{b}}$ & 4 & $2.40 \pm 0.24^{\mathrm{b}}$ & 48 & $2.36 \pm 0.14^{b}$ & F.M., $10 \mathrm{~min}$ & $2.36 \pm 0.17^{\mathrm{d}}$ \\
\hline $80^{\circ} \mathrm{C}$ & $2.28 \pm 0.05^{\mathrm{b}}$ & 5 & $2.37 \pm 0.05^{\mathrm{b}}$ & 96 & $2.34 \pm 0.20^{\mathrm{b}}$ & N.G., $15 \mathrm{~min}$ & $2.09 \pm 0.13^{\mathrm{c}}$ \\
\hline
\end{tabular}

N.G.: normally ground (in a coffee mill) samples; F.M.: freezer-milled samples

Data are the mean of three replicates

Data with the same letter within the same column were not significantly different $(P<0.05)$ 
Table 5. Quantification of lignin after DFRC degradation (mg / g CWM)

\begin{tabular}{|c|c|c|c|c|}
\hline Normally ground, $6 \mathrm{~mL}$ & Straw-W & Straw-B & Fresh asparagus & Stored asparagus \\
\hline Coniferyl alcohol & n.d & n.d. & n.d. & n.d. \\
\hline Conifeyl monoacetylated & $2.31 \pm 0.16$ & $1.15 \pm 0.06$ & $0.08 \pm 0.00$ & $0.12 \pm 0.00$ \\
\hline Coniferyl diacetylated & $2.05 \pm 0.13$ & $1.05 \pm 0.04$ & $0.04 \pm 0.00$ & $0.06 \pm 0.00$ \\
\hline Sinapyl alcohol & $0.93 \pm 0.08$ & $0.46 \pm 0.04$ & n.d. & n.d. \\
\hline Sinapyl monoacetylated & $0.46 \pm 0.05$ & $0.24 \pm 0.03$ & $0.06 \pm 0.01$ & $0.10 \pm 0.00$ \\
\hline Sinapyl diacetylated & $0.66 \pm 0.03$ & $0.28 \pm 0.01$ & $0.02 \pm 0.00$ & $0.02 \pm 0.00$ \\
\hline p-Coumaryl diacetylated & $0.20 \pm 0.01$ & $0.31 \pm 0.02$ & n.d. & n.d. \\
\hline Total monomers yield & $6.61 \pm 0.47$ & $3.49 \pm 0.21$ & $0.20 \pm 0.02$ & $0.30 \pm 0.02$ \\
\hline Freezer milled, $6 \mathrm{~mL}$ & Straw-W & Straw-B & Fresh asparagus & Stored asparagus \\
\hline Coniferyl alcohol & n.d & n.d. & n.d. & n.d. \\
\hline Conifeyl monoacetylated & $2.52 \pm 0.16$ & $2.34 \pm 0.06$ & $0.11 \pm 0.01$ & $1.08 \pm 0.07$ \\
\hline Coniferyl diacetylated & $2.23 \pm 0.07$ & $2.13 \pm 0.21$ & $0.03 \pm 0.00$ & $0.51 \pm 0.02$ \\
\hline Sinapyl alcohol & $1.00 \pm 0.05$ & $0.92 \pm 0.03$ & n.d. & n.d. \\
\hline Sinapyl monoacetylated & $0.50 \pm 0.02$ & $0.50 \pm 0.04$ & $0.08 \pm 0.00$ & $0.89 \pm 0.03$ \\
\hline Sinapyl diacetylated & $0.72 \pm 0.01$ & $0.57 \pm 0.04$ & $0.03 \pm 0.00$ & $0.22 \pm 0.02$ \\
\hline$p$-Coumaryl diacetylated & $0.22 \pm 0.02$ & $0.64 \pm 0.02$ & n.d. & n.d. \\
\hline Total monomers yield & $7.19 \pm 0.33$ & $7.10 \pm 0.41$ & $0.25 \pm 0.02$ & $2.70 \pm 0.14$ \\
\hline Normally ground, $12 \mathrm{~mL}$ & Straw-W & Straw-B & Fresh asparagus & Stored asparagus \\
\hline Coniferyl alcohol & n.d & n.d. & n.d. & n.d. \\
\hline Conifeyl monoacetylated & $6.75 \pm 0.46$ & $5.21 \pm 0.44$ & $0.21 \pm 0.01$ & $1.60 \pm 0.14$ \\
\hline Coniferyl diacetylated & $5.98 \pm 0.19$ & $4.74 \pm 0.12$ & $0.10 \pm 0.00$ & $0.76 \pm 0.04$ \\
\hline Sinapyl alcohol & $2.70 \pm 0.14$ & $2.05 \pm 0.16$ & n.d. & n.d. \\
\hline Sinapyl monoacetylated & $1.35 \pm 0.11$ & $1.11 \pm 0.04$ & $0.15 \pm 0.01$ & $1.32 \pm 0.08$ \\
\hline Sinapyl diacetylated & $1.93 \pm 0.06$ & $1.26 \pm 0.05$ & $0.05 \pm 0.00$ & $0.32 \pm 0.00$ \\
\hline$p$-Coumaryl diacetylated & $0.58 \pm 0.02$ & $1.42 \pm 0.03$ & n.d. & n.d. \\
\hline Total monomers yield & $19.29 \pm 0.98$ & $15.79 \pm 0.84$ & $0.51 \pm 0.03$ & $4.00 \pm 0.27$ \\
\hline Freezer milled, $12 \mathrm{~mL}$ & Straw-W & Straw-B & Fresh asparagus & Stored asparagus \\
\hline Coniferyl alcohol & n.d & n.d. & n.d. & n.d. \\
\hline Conifeyl monoacetylated & $8.26 \pm 0.25$ & $5.81 \pm 0.41$ & $1.27 \pm 0.11$ & $1.68 \pm 0.15$ \\
\hline Coniferyl diacetylated & $7.32 \pm 0.44$ & $5.28 \pm 0.16$ & $0.62 \pm 0.02$ & $0.80 \pm 0.04$ \\
\hline Sinapyl alcohol & $3.30 \pm 0.37$ & $2.29 \pm 0.09$ & n.d. & n.d. \\
\hline Sinapyl monoacetylated & $1.65 \pm 0.13$ & $1.23 \pm 0.08$ & $0.93 \pm 0.03$ & $1.39 \pm 0.07$ \\
\hline Sinapyl diacetylated & $2.36 \pm 0.26$ & $1.41 \pm 0.08$ & $0.28 \pm 0.02$ & $0.34 \pm 0.00$ \\
\hline$p$-Coumaryl diacetylated & $0.71 \pm 0.02$ & $1.58 \pm 0.17$ & n.d. & n.d. \\
\hline Total monomers yield & $23.60 \pm 1.47$ & $17.60 \pm 0.99$ & $3.10 \pm 0.18$ & $4.21 \pm 0.27$ \\
\hline
\end{tabular}

$\mathrm{W}$ : wheat, B: barley. Data are the mean of three replicates 


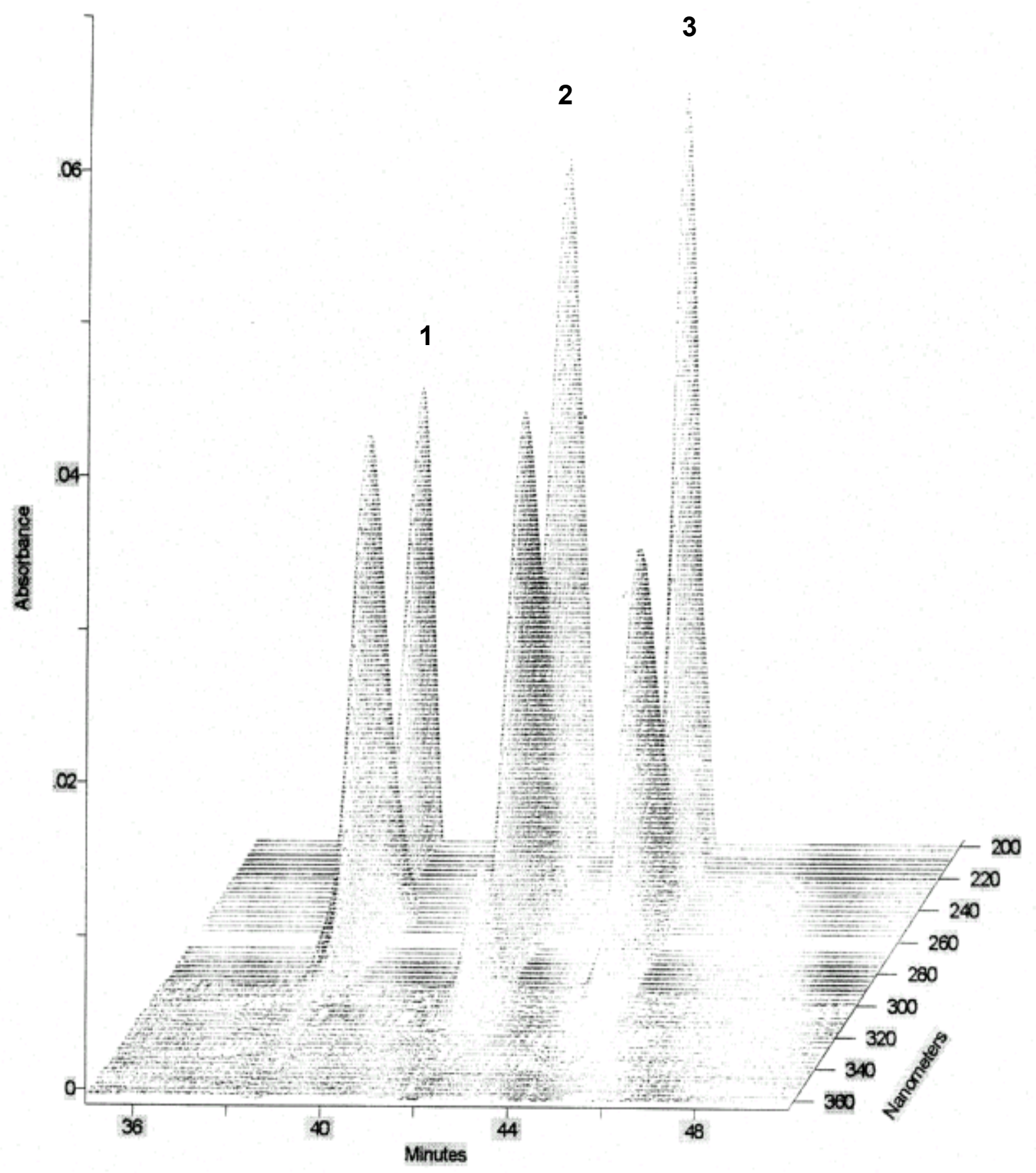

Fig. 1. Three-dimensional elution profile of monomers derived from DFRC degradation of lignin samples, detected by DAD scanning between 200 and $360 \mathrm{~nm}$. 1, pcoumaryl peracetate, 2 , coniferyl peracetate, 3 , sinapyl peracetate. 
A)

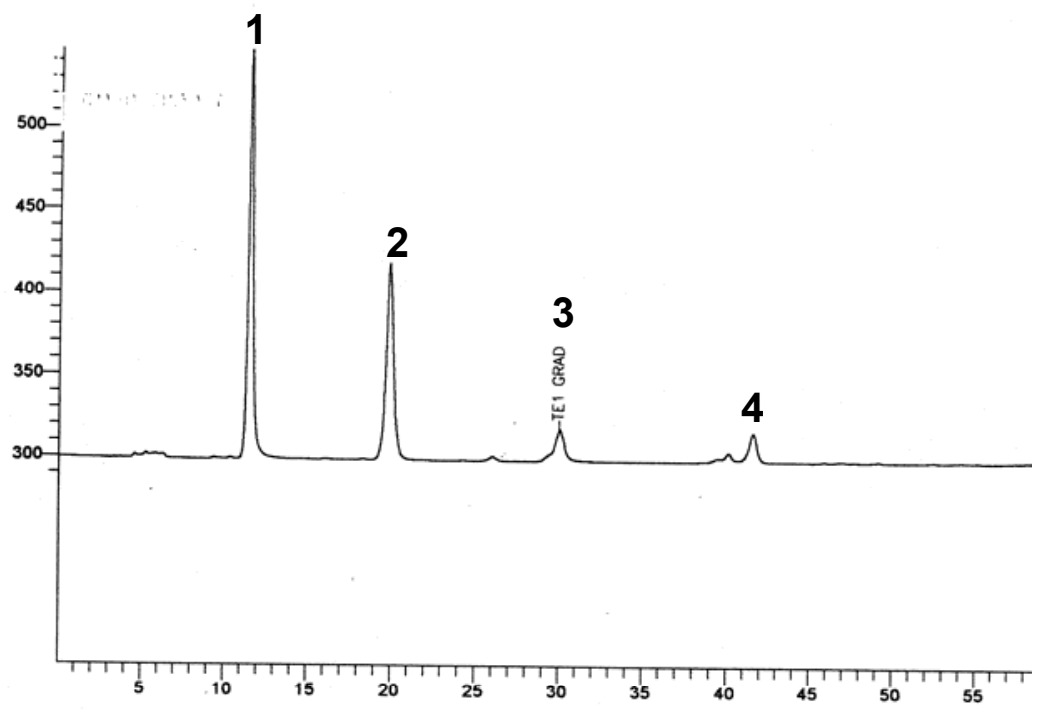

B)

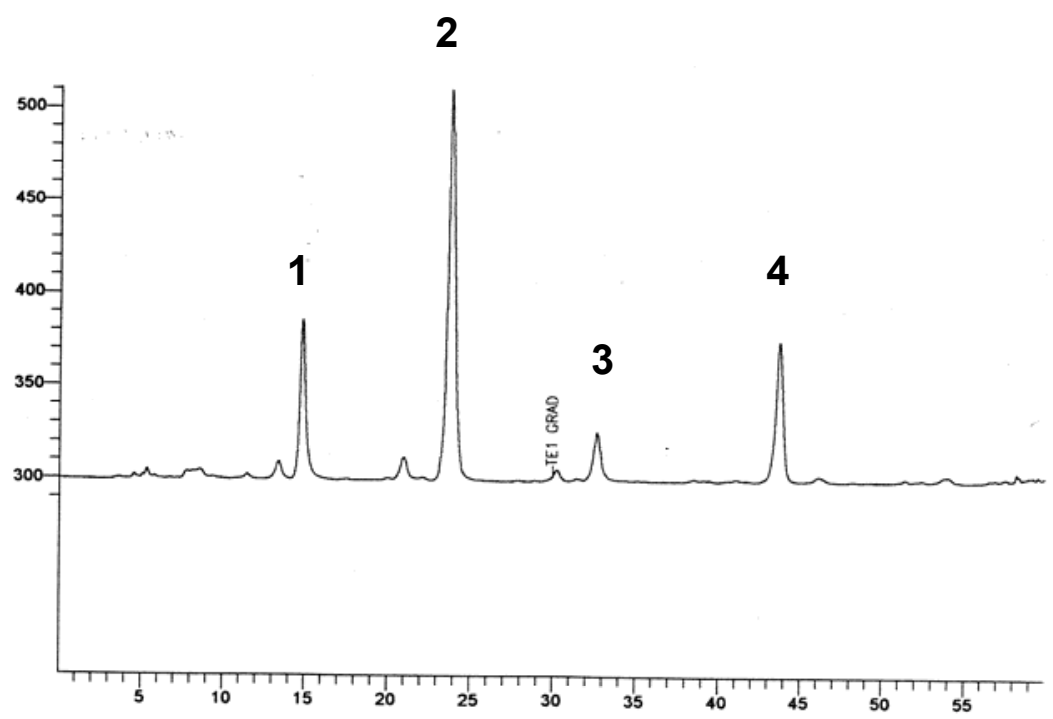

Fig.2. HPLC elution profile of: A) coniferyl derivatives. 1, coniferyl alcohol, 2, coniferyl monoacetylated A, 3, coniferyl monoacetylated B, 4, coniferyl diacetylated; B) sinapyl derivatives. 1, sinapyl alcohol, 2, sinapyl monoacetylated A, 3, sinapyl monoacetylated B, 4, sinapyl diacetylated 


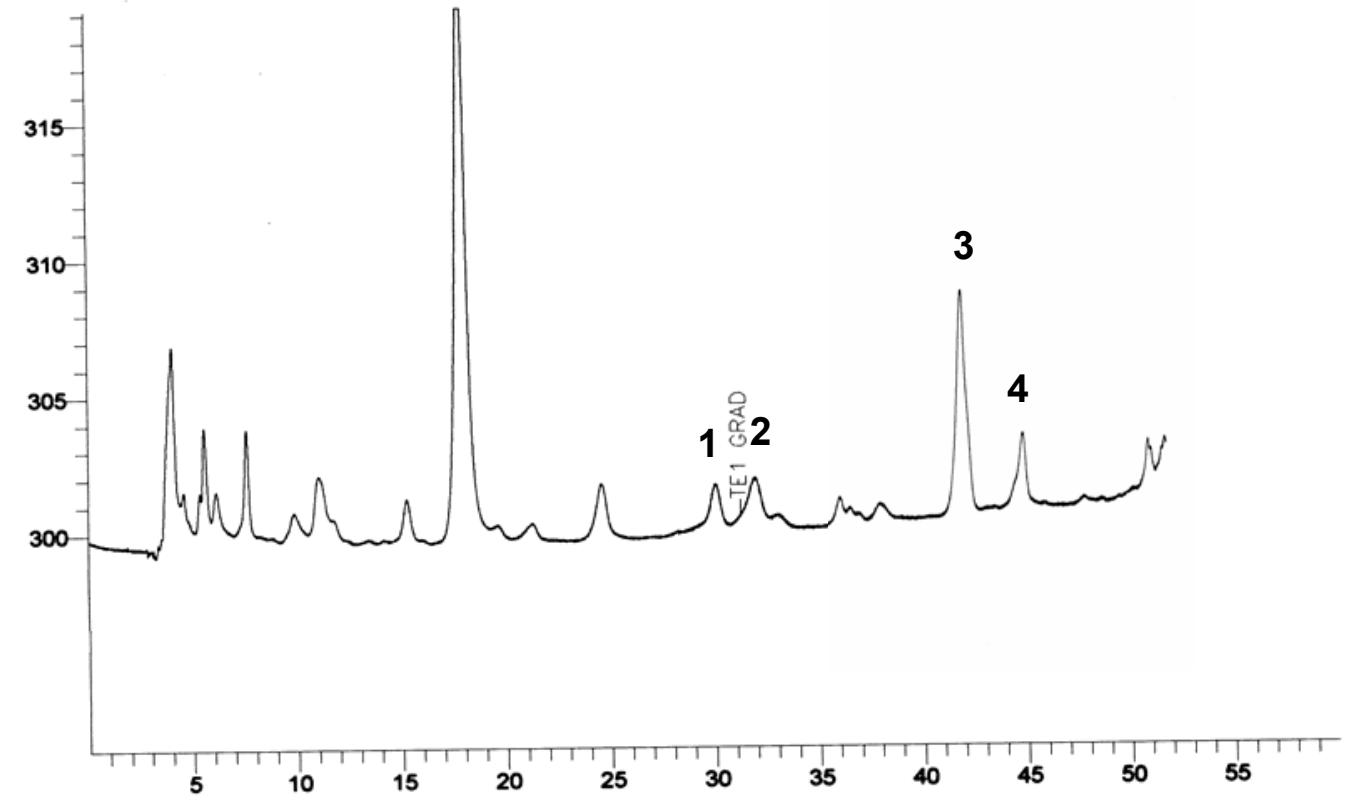

Fig. 3. HPLC elution profile of lignin components of asparagus cell wall. 1, coniferyl monoacetate B, 2, sinapyl monoacetate B, 3, coniferyl diacetate, 4, sinapyl diacetate. 